\title{
Cryogenics as an Advanced Method of Cleaning Cultural Heritage: Challenges and Solutions
}

\author{
Aina Vega-Bosch *(D), Virginia Santamarina-Campos $\mathbb{B}$, Antoni Colomina-Subiela $\mathbb{D}$ \\ and María-Ángeles Carabal-Montagud (i)
}

Department of Conservation and Restoration of Cultural Heritage, Faculty of Fine Arts, Polytechnic University of Valencia, 46022 Valencia, Spain; virsanca@upv.es (V.S.-C.); ancosu@upv.es (A.C.-S.); macamon@crbc.upv.es (M.-Á.C.-M.)

* Correspondence: aivebos@bbaa.upv.es; Tel.: +34-607919551

check for updates

Citation: Vega-Bosch, A.; Santamarina-Campos, V.; Colomina-Subiela, A.;

Carabal-Montagud, M.-Á.

Cryogenics as an Advanced Method of Cleaning Cultural Heritage:

Challenges and Solutions.

Sustainability 2022, 14, 1052.

https://doi.org/10.3390/

su14031052

Academic Editors: Constantin

Bungău, Gheorghe Nechifor and

Lucian Copolovici

Received: 29 November 2021

Accepted: 14 January 2022

Published: 18 January 2022

Publisher's Note: MDPI stays neutral with regard to jurisdictional claims in published maps and institutional affiliations.

Copyright: (c) 2022 by the authors. Licensee MDPI, Basel, Switzerland. This article is an open access article distributed under the terms and conditions of the Creative Commons Attribution (CC BY) license (https:// creativecommons.org/licenses/by/ $4.0 /)$.

\begin{abstract}
The conservation and restoration of cultural heritage rely on technology and products designed for other sectors. The incorporation of new equipment requires exhaustive studies to ensure the viability of the new method linked to the safety of the technique, both for the operator and for the artwork. For this purpose, this research presents a preliminary approach to the study of dry ice blasting for its possible incorporation in the field of cultural heritage. This technique is characterized by being harmless for the operator and does not require washing times or subsequent evaporation as a result of solvent retention. It is an efficient and sustainable treatment, widely used in the technological, aerospace and industrial sectors. The article shows a theoretical analysis of the research results obtained by other specialists with the aim of introducing this technique in the eco-sustainable study of innovative technologies for the cleaning of culturally relevant surfaces. It describes the procedure of cryogenics, some cleaning equipment currently available and relevant case studies for both industrial and patrimonial contexts. Through the compilation and processing of documentary sources, we will be able to understand, define and analyze this new technique, specifying some basic aspects for its experimental evaluation. The attempt to incorporate cryogenics in the field of heritage is an improvement towards the reduction of the ecological management derived from the use of chemical waste. It is an innovative resource, full of benefits for the sector, in addition to contributing to five Sustainable Development Goals of the 2030 Agenda. This contribution allows progress towards a safer, greener and more sustainable restoration, reducing the dangers associated with the use of solvents and their irremediable ecological impact.
\end{abstract}

Keywords: cultural heritage; dry ice blasting; cryogenics; cleaning; sustainability; innovation; Agenda 2030; sustainable development goals

\section{Introduction}

The cleaning of cultural heritage is one of the most complex and controversial treatments in the restoration process. It is an invasive and irreversible intervention that should not compromise the future conservation of the property [1]. Therefore, we define cleaning as a process that includes the removal or reduction of layers that could have been deposited on the artwork after its creation. The reason for its removal is due to its condition, which no longer responds adequately to its functionality, or the aesthetic impact, altering the perception of the image and its symbolic discourse [2]. The approach is fundamentally aesthetic and is not intended to jeopardize or alter the physical and mechanical properties of the surface to be preserved; moreover, its irreversibility requires maximum prudence and responsibility [3]. The terminology that is usually used to refer to this type of treatment requires deep analysis in order to distinguish the superficial cleaning from the one that pretends to eliminate the layers that are part of the pictorial stratification [4]. For this purpose, new methods have been designed to develop layer-by-layer cleaning systems, improving 
safety and control over the effects on the material to be preserved. This response is the first removal of accumulated deposits such as environmental dirt or contaminating particles as surface cleaning, followed by a second treatment for the elimination of polymers and more complex cross-linked structures, as layer removal.

In order to define the suitability of a method, it is important to pay attention to aspects such as brightness, saturation or hue, which can be evaluated macroscopically with non-invasive analysis techniques. However, invasive studies should be available to assess alterations in the polymeric and even topographic structure of the material. Access to analytical techniques provides essential information for the election of the most appropriate treatment. In this way, a safety procedure is established to guide the complex decision-making process preceding a cleaning treatment [2].

Nowadays, research on the cleaning of cultural heritage surfaces is still trying to solve some of the great challenges faced by restorers. Considering the basic requirements of an innocuous cleaning [1], the sensitivity of some paints to chemical and aqueous solvents, the irregular or inaccessible morphology of many surfaces and the insolubility of certain substances usually determines the treatment. Sometimes the elimination of some substances must be ruled out in order to avoid greater risks to the original layers. Unfortunately, the aesthetic consequences also pose a risk to the artwork. We recall that cleaning consists of removing any substance that is foreign to the nature of the artefacts. This residue interacts detrimentally with its conservation and can be linked to both aesthetic and chemical factors $[5,6]$. The treatment requires an analysis of priorities, from an interdisciplinary approach and consensus, in order to preserve the integrity and authenticity of the cultural object [7]. Additionally, sustainability criteria must be involved in order to maintain the affinity of the cleaning method with the needs of the object to be preserved [8]. Nevertheless, specific lines of study are initiated from these challenges and contribute to new strategies, which are also useful in other areas of cultural heritage conservation. In the case of contemporary paintings without a protective layer, we see abundant studies that advocate finding a solution to the cleaning of this type of surface. The research of physical, chemical, mechanical and biological methods has advanced towards gelled, soapy, emulsifying and ionic systems [3,9-12], including photoablation [13-16], with the idea of reducing the risks associated with the treatment of this type of artwork [7], in addition to the reduction of toxicity and environmental impacts. The study of phenomena caused by the use of solvents, such as leaching or extraction of soluble polymeric substances, continues to provide information on the effect that these solubilizing agents have on the pictorial films and is also linked to the washing procedures and elimination of non-volatile residues deposited by the cleaning system $[17,18]$. In this sense, the research proposes alternatives to solve current problems through the adaptation and incorporation of new and alternative methods, from which we can approach the coherence required by the treatment in order to minimize risks for the artwork, the restorer and the environment.

The incorporation of dry ice blasting as an alternative to other cleaning systems in the field of conservation and restoration of cultural heritage is an action committed to the 2030 Agenda, as well as a technical advance in the methodologies applied for the removal of unwanted layers. The innovative combined action of kinetic energy, thermal energy and sublimation of the projected material represents a new mechanical cleaning tool with no risk of abrasion or secondary residue [19-21]. This new technique consists of the micro-projection of solid $\mathrm{CO}_{2}$ combined with compressed air, whose initial temperature reaches $-79{ }^{\circ} \mathrm{C}$ and $-18{ }^{\circ} \mathrm{C}$, dry ice blasting and snow blasting, respectively. Dry ice extrusion produces cylindrical and amorphous particles, characterizing two different cleaning methodologies [20,22]. Dry ice blasting removes the deposit through a combined thermomechanical effect. This consists of cold induced by the projectile, kinetic energy transmitted by the blasting of the dry ice, and sublimation of the cryogenic material, whereby the residue derived from the treatment is transformed into a gas [19]. This last phenomenon has a great ecological impact, as it completely reduces the treatment of waste derived from the equipment. The adaptation of the pressure, airflow and feed rate 
parameters allow working on delicate surfaces [20]. This is why its use in the field of conservation and restoration has found applicability among synthetic polymers applied on walls or waxy coatings on metal matrices, as well as soot residues and environmental dust conglomerates on bibliographic collections, among others $[23,24]$. However, studies are needed to support its application on other surfaces and to optimize the suitability of the method in order to corroborate the responsible and prudent use of this technology [2].

The general purpose of the research is to consider the inclusion of dry ice blasting as an innocuous, innovative and sustainable alternative to the cleaning systems commonly used in the field of conservation and restoration of cultural heritage, with problems related to the residue, toxicity, and retention. To achieve this objective, specific goals were defined. On the one hand, we seek to reduce toxicity in cultural heritage cleaning operations by providing sustainable alternatives. To this end, the adaptation and optimization of dry ice blasting for a selective, precise and efficient application in this area are now underway. The results will be published upon completion. The dissemination of the advances obtained allows us to open a line of study and research that provides new avenues of development in the study of ecological and sustainable cleaning systems while applying and complying with the SDGs and the 2030 Agenda, encouraging and promoting them.

Dry ice blasting thus contributes to ensuring access to affordable, reliable, sustainable and modern energy for all (SDG 7) by adding an innovative, sustainable, efficient and costeffective technological alternative to the range of cultural cleaning techniques (SDG 7.3.b). It also calls for promoting sustained, inclusive and sustainable economic growth, full and productive employment and decent work for all (SDG 8), as well as promoting the building of resilient infrastructure, advocating inclusive and sustainable industrialization and fostering innovation (SDG 9). At the same time, it aims to ensure sustainable consumption and production patterns (SDG 12) by converting the by-products that arise from industrial processes into projectable $\mathrm{CO}_{2}$ pellets. These pellets are subsequently derived to cryogenics applied to the industrial sector for dry ice blasting or the preservation of food and vaccines, among other applications. In this way, energy waste is avoided through innovative and sustainable consumption and reuse processes (SDG 8. 4, 9.4, 9.5.b, 12.2). Finally, it recognizes the need to take urgent action to combat climate change and its impacts (SDG 13). As a research project linked to a university degree, it brings environmental awareness closer to the classrooms and departments of the institution (13.3) [25].

\section{Methods}

Qualitative research was carried out for the research work. For this purpose, we focused on the study of documentary sources, consulting the different texts published on the subject in books, conference proceedings, specialized journals, monographs, reports, equipment data sheets and videographic records. In this way, we have been able to determine the state of the art, both at national and European level. The review has focused on the study of the tool in the technological $[20,26]$, food $[27,28]$ and industrial sectors $[22,29,30]$, as well as in the restoration and conservation of cultural heritage [21,31,32]. The methodology used for the content analysis was based on a bibliographic review of 409 documents, as well as the analysis of the technical data sheets of 20 cryogenic equipment of the brands Kärcher, PolarTech, ColdJet, AQUILA Triventek, INTELblast, Cryoblaster, CryoSnow and Cryoclean, whose representativeness in the available market is enough to understand the operational ranges of the commercially offered devices. In addition, 52 intervention reports from multiple disciplines were analyzed, including study cases in cultural heritage where this technology has been successfully used. As a result of the evaluation of other techniques involved in this study, 82 resources of primary, secondary and tertiary information were studied. Through these published reports, relevant information has been extracted both for this study and for future experimental research projects. Research has been achieved through Scopus search patterns: (cleaning AND cryogenic) limiting the area to Engineering, Materials Science, Energy, Chemistry, Chemical Engineering, Environmental Science; also 
adding keywords such as cultural heritage; dry ice blasting; sustainability; innovation; technical sheet; report.

The work plan was formulated in the first place through the location of archives and the collection of information of interest consulted in them, followed by organizing the set of documents to develop a first critical, analytical and interpretative exercise. Then we proceeded to define the theoretical framework, from the analysis and interpretation of the information. Finally, a proposal for implementation and the drawing of conclusions.

\section{State of the Art}

Cryocleaning emerged in 1985 in the United States as a patent designed and developed by Cold Jet [31] primarily for pickling and coating removal [30]. It is a system with low environmental impact, easy transfer and infinite applications without compromising the original preservable materials [19]. The main studies related to the method are mainly from the aerospace, technology and automotive industries, where it is used to clean electrical circuits, sterilize cabinets and prepare surfaces for the application of coatings. $\mathrm{CO}_{2}$ microspraying is safe for electrically conductive components, as it is a dry process with no risk of a short-circuit. In turn, the particle size of the deposit to be removed does not alter its effectiveness, so it can also be used for surface disinfection. These and other industrial applications provide information on the versatility of the method. We can recognize possible applications in the field of heritage restoration, such as removal of polymers, environmental fouling, or microorganism colonies. In order to be validated as a technique applicable to sensitive surfaces with overlapping layers of different natures, the results should be subjected to experimentation and quantitative analysis for system optimization. The introduction and application of a new cleaning technique in the field of conservation of cultural heritage is always a challenge. The basic requirements demand an in-depth study of the physico-chemical mechanisms involved in the removal process, with the aim of keeping the underlying stratum intact. Even so, it is important to highlight the interest that surrounds this tool in other sectors and the excellent results that have been obtained in some interventions on cultural heritage $[27,32]$.

The limitations of this technology must be taken into account. The type of bonding between layers will determine the effectiveness of the treatment. Cryocleaning is able to remove layers whose bonding with the matrix is weak, i.e., those bound by Van der Waals forces, electrostatic bonds or capillary forces, but cannot break stronger chemical bonds [32]. Aspects such as the precision, control or selectivity of the method, along with the secondary residue derived from it and its toxicity, must inevitably be evaluated when developing a reasoned cleaning protocol. The treatment may be considered harmless when the materials deposited on the surface structure are selectively removed. This means avoiding the alteration of the surrounding materials, mainly the ones belonging to the original polymeric structure $[5,6]$.

A review of the historical evolution of the materials used by conservators and restorers showed that it was common to use aggressive methods, with limited knowledge about the control and interaction with the solute. Aspects such as penetration, retention, volatility or toxicity of chemicals used for restoration treatments have only been evaluated scientifically over the last few decades. There was poor control over the safety of cleaning treatments, which usually resulted in abrasions, leaching or dissolution of the original polymer structure of the paintings. Nowadays, we notice this in artworks that come back to restoration laboratories with significant damage caused by aggressive cleaning. However, resources from science were invested in the study of organic solvents and soapy substances, enabling the regulation of aggressiveness in cleaning treatments [33]. Even so, the toxicity and sustainability of some products continue to have a severe environmental impact, which makes it necessary to consider the inclusion of eco-compatible systems that are harmless to the restorer $[9,34]$.

Unfortunately, we still have the problem of non-volatile residues deposited by the safest and most advanced cleaning products, although it is a line of research that is finding 
a solution in nanoscience $[9,35]$ and other methods in which completely volatile materials are also involved $[2,9,36]$. We can define the residue as that solid or liquid substance that is retained in the structure of the layer after treatment [6]. This deposited material can interact with the original polymer and trigger its degradation. The most significant drawbacks are noted in contemporary artistic productions, as changes in the polymeric structure caused by the extraction of soluble additives induced by the residue or solvent treatment [37].

\section{Results}

The investigation of cryocleaning for its use in the heritage sector offers an innovative, respectful, sustainable and efficient alternative to other methods whose toxicity, abrasion or long application times disqualify them. Its use is most widespread in other sectors, so the analysis is based on research developed for those areas in which it is commonly applied $[19,20,27]$.

Dry ice is accessible and cost-effective. Its production is obtained by the compaction of by-products derived from industrial waste [27]. The recycling of this material for the manufacture of pellets and liquid $\mathrm{CO}_{2}$ contributes to the preservation of the sustainable production and use line, reducing the emission of gases and pollutants into the atmosphere. The peculiarity of solid carbon dioxide lies in its ability to sublimate when it hits the surface, turning into a gas without leaving any residues [19]. Therefore, the management of waste resulting from the treatment is avoided.

The combination of dry ice, electricity and compressed air has been used for the removal of pictorial layers such as enamels, polymers or environmental dust deposits, while its use has also been extended to the medical, pharmaceutical and food industries for environmental and surface sterilization, as well as in the metallurgy and plastics industries, for deburring and cleaning molds [27].

The following sections describe the process, the application and some cases in which the system has been used, both industrial and heritage conservation, in order to exemplify the technical study of the tool and illustrate its adaptability and effectiveness.

\subsection{How It Works}

Cryocleaning consists of the micro-projection of solid $\mathrm{CO}_{2}$ combined with compressed air. Dry ice in pellet form, or dry ice blasting, is produced through the extrusion and fragmentation generated by pelletizers, which submit carbon dioxide to high pressures and temperatures close to $-79{ }^{\circ} \mathrm{C}$ to obtain large blocks from which to extract cylinders of usually $3 \mathrm{~mm}$ in diameter $[20,22]$. However, there is an alternative variant called snow blasting, whose $\mathrm{CO}_{2}$ projection is produced from the material in a liquid state, obtaining an amorphous mist subjected to $-18^{\circ} \mathrm{C}$ [38].

The operation of dry ice blasting on the material to be removed is achieved through a combined thermomechanical effect. The cleaning process involves simultaneously the thermal shock induced by the temperature of the projectile, the kinetic energy that accompanies the propulsion of the material and the sublimation energy that triggers the phase change [19]. The compressed air serves as a projection medium, and its cleaning action is almost null [29]. It should be remembered that the effectiveness of the method depends on the type of bonding between layers, as it is able to break only weak bonds such as Van der Waals forces, electrostatic bonds or capillary forces [32].

The sublimation of the projectile facilitates the subsequent treatment of the area by sublimating instantaneously, completely reducing the management of derived waste. Only the de-cohesioned remnants of the unwanted layer will remain on the working area [22].

\section{- Thermal effect}

The initial temperature values of pellets are close to $-70{ }^{\circ} \mathrm{C}$ [26], while those of carbonaceous snow are $-18^{\circ} \mathrm{C}$ [38]. These temperature settings do not remain thermostable during the cleaning process, rising slightly and gradually as they enter into the machine circuit, from the storage tank to the firing nozzle. Thus, the surface temperature values 
measured after micro-projection with dry ice are $-12{ }^{\circ} \mathrm{C}$ [19], while the minimum taken by thermal imaging (FLIR 320EX) after snow blasting is $8.1^{\circ} \mathrm{C}$ [39].

The impact of the projectile on the deposit to be removed produces a regional decrease in the surface temperature, triggering alterations in the mechanical properties of the deposit. As a result of the thermal shock, the elasticity of the layer is reduced, making it less resistant and, consequently, more friable. At the same time, a macroscopically visible network of cracks is generated as a result of the shrinkage of the material, evidencing the different expansion coefficients of the layer. This results in a weakening of the forces that bind it to the matrix, causing its detachment (Figure 1) [19].

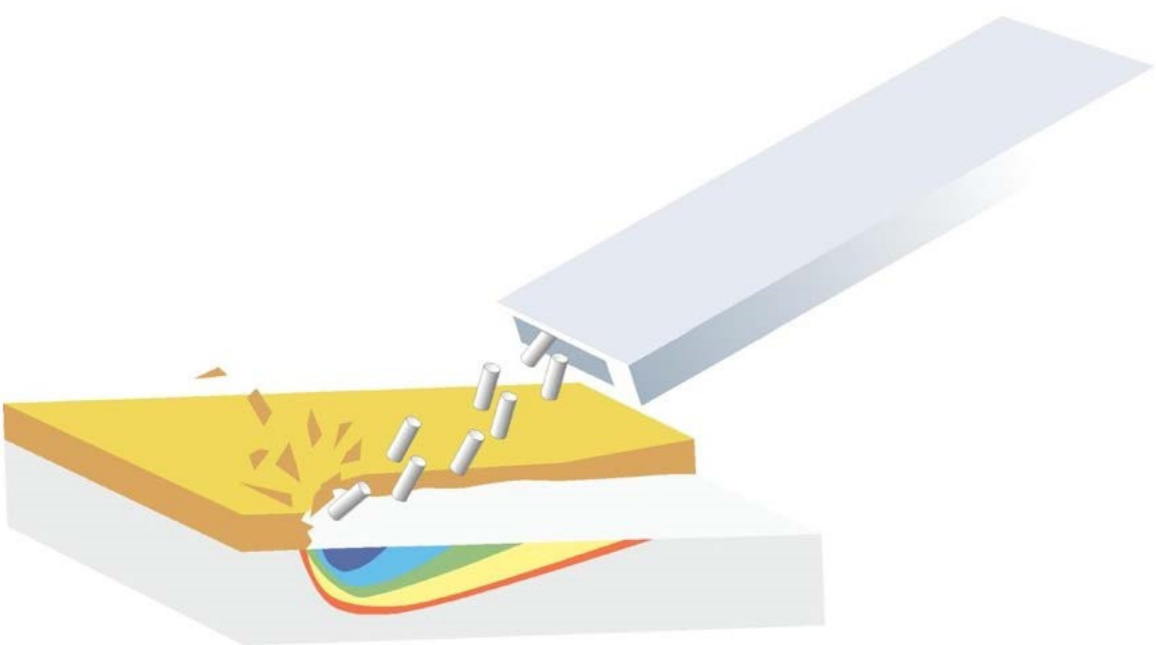

Figure 1. Action of dry ice blasting on the undesired layer. Descriptive diagram of the removal of unwanted layers (yellow) while keeping the underlying matrix intact (gray). The impact of pellets is depicted next to the gradual alteration of surface temperature. Source: Developed by the authors, 2021.

\section{- $\quad$ Kinetic energy}

This corresponds to the pressure with which the jet propels the sprayed material and is considered to be directly proportional to the effectiveness of the method [20]. While some authors consider this to be the main factor responsible for the cleaning process [21], others differ, taking the view that $30-40 \%$ corresponds to kinetic energy and the remaining $60-70 \%$ to temperature $[19,40]$.

This energy is linked to the power of the machine and, consequently, the power with which the $\mathrm{CO}_{2}$ impacts [40]. However, the nozzles attached to the gun, the pellet dimensions or the hose diameter also affects the process. In addition to this, the angle of projection increases in efficiency with lower gun inclination angles, i.e., closer to the plane [21].

\section{- Sublimation energy}

The solid $\mathrm{CO}_{2}$ sublimation process is inevitably involved in the cleaning treatment. It fulfills a double function as it is responsible for the phase change of $\mathrm{CO}_{2}$ from solid to gas. On the one hand, it facilitates the cleaning process by volatilizing any residue used during spraying, being a great advantage of the method. On the other hand, it acts on the weakened joints of the laminate layers, affected by the thermomechanical effect. The expansion that occurs during sublimation produces an increase in the pressure between layers, promoting the rupture of bonds and the elimination of the material (Figure 2) [19]. 

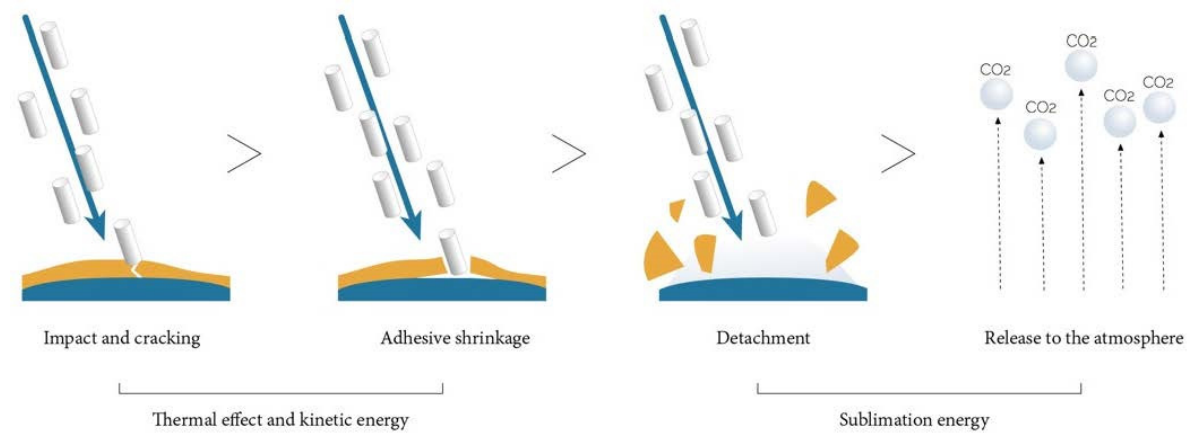

Figure 2. Process diagram of the removal procedure. Source: Developed by the authors, 2021.

\subsection{Review and Characterisation of Available Equipment}

Dry ice blasting has found a niche market for the provision of services in industrial factories, where there is a need to remove large accumulations of deposits attached to electrical circuits or machinery with limited accessibility. The application of this technique does not require the dismantling of the equipment or subsequent treatment, such as waste disposal or solvent evaporation, thus reducing service downtime [30]. The food industry strongly benefits from this technique by avoiding the contact of chemical products with the operating surfaces. This means that the high requirements for sanitary conditions or the daily challenges of industrial production are not compromised. Companies dedicated to the development of technological components also find the projection of solid $\mathrm{CO}_{2}$ to be a solution that eliminates environmental deposits from electrical circuits without compromising their conductivity [27]. In addition, sites of public interest or free access, such as buildings or areas of political and public relevance that are subject to contamination and exposed to vandalism, also perform well with cryocleaning treatment [41].

The equipment available nowadays is designed to be adaptable to the most common cases in the industry, including large and inaccessible areas, regular and irregular accumulations of deposits or materials of very variable composition. All dry ice blasting machines enable the reduction of the treatment times expected of traditional cleaning, with the idea of minimizing production stoppages and reducing worker exposure to chemical products and subsequent treatments linked to a second washing or the removal of residual material as occurs with micro-abrasive sandblasting.

Regarding the companies dedicated to the supply of these services, we found national and international markets focused on both the sale and hire of equipment, as well as the supply of $\mathrm{CO}_{2}$ in the liquid and solid state, sometimes accompanied by an operator responsible for carrying out the treatment. Some of these companies focus on the development of new machines, being pioneers in the innovative design of new cryocleaning devices. Among them, we found the Barcelona-based company ICEco ${ }^{\circledR}$ \& INTELblast ${ }^{\circledR}$ at the national level. Research and technological advances in this field are also relevant in other countries, such as PolarTech ${ }^{\circledR}$ in Odense and Aquila Triventek ${ }^{\circledR}$ in Nørre Aaby, both in Denmark; Cryoblaster in Frontonas (France); ColdJet ${ }^{\circledR}$ in Loveland (OH, USA); and Kärcher $^{\circledR}$ in Winnenden (Germany). All of them have Spanish subsidiaries as well as links to other distribution companies, improving the accessibility of this new equipment, whose developments are promoting an increase in the efficiency and adaptability of the devices.

The effectiveness and efficiency of the cleaning process will be linked to the ability to control the variables of pressure, volume and size of the projected material. Some devices have more rudimentary control systems, while others include small processors with a control screen, where the regulation is more precise and verifiable [42].

The inclusion of dry ice blasting in the industry solves the important challenge of reducing exposure times, toxicity or subsequent waste removal tasks. The parameters of the equipment can be adapted to the type of substrate, accessibility, surface topography or the dimension of the working area. For that reason, it is equipment capable of being adapted to the particular needs of each industrial field. The sectors in which this method is 
applied range from the food industry, in processing plants, food transport, preservation of raw materials or their refrigeration, to the pharmaceutical industry, with the preservation of reagents. Its application in the sterilization of aircraft cockpits and other areas has also been mentioned previously. In rubber and plastic processing, its use is focused on deburring or cutting alloys in metallurgy [43].

The industrial characterization of the substances to be removed is considerably limited. We usually found companies whose promotion of the treatment is directly linked to exemplifying the infinite applications for a specific sector, emphasizing the adaptability of the machine by means of audiovisual and illustrative material on its operation on different surfaces. Occasionally a technical description of the cleaning treatments is given, which allows us to become closer to the characterization of the removed material. Discrimination based on water affinity is common, such as hydrophilic lime coatings or hydrophobic accumulations of lubricant in gears. In turn, the hardness of the solid differentiates a cement coating from traces of adhesives, inks or rubbers. The stratification of sediment layers is also taken into account. Those that are more compact correspond to crusts, while the partially powdery ones will be the remains of soot and environmental dust. Other aspects such as the layer thickness or working surface characterize glazes or large mixed accumulations of grease and dust, as well as smooth and homogeneous surfaces versus others that are rough and difficult to access. Examples of the latter are machines consisting of interlocking couplings, circuits or ducts, as well as rough stone walls or roofs.

Depending on the type of stratum, the equipment will be adapted in terms of components, pressure values, pellet size or the quantity of $\mathrm{CO}_{2}$ projected. Some equipment has control monitors, from which cleaning profiles can be created to facilitate the reproducibility of the treatment, allowing the evaluation and review of the results. This advance enables systemized applications and increased knowledge of the values of the pressure, granulometry or feed rate used in each case.

The measurement of blast pressure levels is represented in Bar (bars), using AngloSaxon equipment whose system is PSI (pounds per square inch). These values are directly proportional to the abrasion of the method, meaning that high pressures will have a greater effect on hard and compacted strata. The particle size is usually reflected in millimeters, and the pellets are usually between $0.3 \mathrm{~mm}$ and $3 \mathrm{~mm}$. A larger size of the projectile will cause more significant impacts at the thermomechanical level, increasing the temperature and expansion by sublimation of the material. The smaller size material enables more delicate work, with greater control over the matrix [27]. The last two agents involved in the process are the cooling rate and the airflow rate, whose adjustment links them directly to each other. The rate corresponds to the amount of material sprayed per hour $(\mathrm{kg} / \mathrm{h}$ or $\mathrm{lb} / \mathrm{min}$ ) and affects the autonomy of the equipment, depending on the $\mathrm{CO}_{2}$ capacity of the tank, while the airflow rate is translated into $\mathrm{m}^{3} / \mathrm{min}$ (Table 1 ).

Table 1. Values involved in the adjustment of the machine. Range of minimum and maximum values among the equipment studied.

\begin{tabular}{cc}
\hline Parameter & Value Range \\
\hline Air pressure & $2-16 \mathrm{bar}$ \\
Feed rate & $0-160 \mathrm{~kg} / \mathrm{h}$ \\
Airflow rate & $0.3-12 \mathrm{~m}^{3} / \mathrm{min}$ \\
Pellet size $\varnothing$ & $0.3-3 \mathrm{~mm}^{1}$ \\
\hline
\end{tabular}

${ }^{1}$ Author's original table based on company product sheets: IB 15/20, 18 7/40 Adv (Kärcher ${ }^{\circledR}$ ); PT 25, PT MINI $\left(\right.$ PolarTech $\left.^{\circledR}\right) ; \mathrm{AERO}_{2}$ PCS60, AERO 2 PLT $60\left(\right.$ ColdJet $\left.^{\circledR}\right) ;$ BL 60 (Aquila Triventek ${ }^{\circledR}$ ); IBL 3000, IBL 4000, IBL Mini (INTELblast $^{\circledR}$ ); ATX25-E (Cryoblaster $\left.{ }^{\circledR}\right)$.

Finding the right combination of necessary parameters is a prelude to the choice of couplings. The nozzles are used to adjust the cleaning to the requirements, with a wide range of nozzles (straight, angular and curved) whose projection mouth can be cylindrical or flat fan-shaped. Their length ranges from $55 \mathrm{~mm}$ to $1 \mathrm{~m}$, with diameters less than $1 \mathrm{~cm}$ [27] (Table 2). 
Table 2. Types of nozzles according to shape, projection mouth and size.

\begin{tabular}{cc}
\hline Morphology & Straight, angular, curved \\
Projection output & Cylindrical, flat fan \\
Length & $55-1000 \mathrm{~mm}$ \\
Diameter & $<1-10 \mathrm{~cm}^{2}$ \\
\hline
\end{tabular}

2 Table based on the ColdJet $^{\circledR}$ company catalogue.

\subsection{Review of Applications and Uses in Cultural Heritage}

The control and safety of dry ice blasting is mainly governed by the hardness of the stratified materials. Therefore, the unwanted deposit must be softer than the matrix to prevent damage to the underlying materials [40].

Its use in architectural heritage, where the working areas are large and vertical work is required, can considerably reduce the usually long and costly working times. The precision of the cleaning facilitates the preservation of the features of the architectural surfaces and their decorations. An example is the restoration of the Art Deco style entrance of the hangar of the American Airways (Texas) airline, made of aluminum in 1933. Good results were also reflected in the metal decoration of Cincinnati's Union Terminal or the bronze fountain at the National Gallery of Art in Washington, Ohio and D.C., respectively. In these, mineral and environmental deposits were removed, along with traces of silicone and other polymers, without altering the historical features of the building [27].

At the Auschwitz-Birkenau State and Memorial Museum in Oswięcim (Poland), smaller objects were treated, such as bowls and spoons of the concentration camp prisoners, having ceramic and metallic matrices [44]. In turn, on eastern military helmets from the Wallace Collection Museum in London, re-coatings applied in old restoration interventions, combined with areas of corrosion and environmental fouling, were successfully removed [45].

This method allows a rigorous and safe cleaning adjustment, as corroborated by its application on fine metallic patinas close to organic materials. One such piece belonging to the museum of the University of Pennsylvania is a Japanese Wakizashi sword of the Edo Period. The hilt of the object was made of silk and leather ribbons, braided on a copper matrix. The metal structure showed corrosion superimposed on a fine black patina, in addition to an accumulation of environmental deposits. The treatment results allowed the conservation of the patina and the alterations inherent to the use of the piece, eliminating the corrosion products that extended to the braided areas [32].

Its use on the sculpture Bronze Form (1986) by Henry Moore surprised several researchers. The work required the replacement of a transparent acrylic-urethane coating applied in previous interventions. With solid $\mathrm{CO}_{2}$ projection, they were able to remove the acrylic polymer without compromising the surface features of the artist's work, whose subtlety required a major compromise with the abrasion levels of the equipment [27,46].

As well as being able to remove polymers, cryocleaning is also useful for the cleaning of aesthetics. The restoration team of the Smithsonian American Art Institute treated the piece Model (1967) by Robert Morris in 2009 [21]. The artist made a series of works in cellulose acetate butyrate $(\mathrm{CAB})$, whose minimalist monochromatic aesthetics pose a great challenge for their conservation. The sculpture showed accumulations of dust and a whitish appearance, which was sampled and analysed inconclusively. However, all the factors pointed to the typical surfactant migrations of this type of material. The use of dry ice blasting revealed the original reading of the artwork, recovering the vibrancy of the color and the homogeneity required by the artist during its conception. The same restoration team repeated the treatment on the polyester sculpture Untitled (1974) by Frederick Eversley, eliminating fingerprints and surface dirt, returning it to its original spectacular appearance.

The effect of the system on cellulosic material achieved good results, eliminating dirt residues of a few microns integrated into the network of paper fibers. Qualitative studies were carried out to evaluate the effectiveness, with favorable conclusions [27]. At the Sevier County Recorder's Office in Richfield (Utah), a fire ravaged the collection, causing soot 
and other debris to be deposited on the books farthest from the fire. The cleaning was satisfactory and efficient, working on six books per hour without producing alterations in the rest of the materials used for covers and sheets [27].

The Research and Technical Assistance Institute and the Environmental Protection Agency have introduced cryocleaning combined with soybean oil for graffiti removal in the city of San Francisco [40,47]. The applicability of the method for the elimination of street interventions is interesting and complex. The combined thermomechanical action is suitable for the removal of plastics of high hardness and low thickness; however, the accessibility of the $\mathrm{CO}_{2}$ beam to the interstices of the support will determine the result [40].

Some researchers have taken the risk of applying the technique on a layer of similar hardness as the substrate, with satisfactory results. A study case involved the New Schleißheim, a palace located north of Munich, built between 1701 and 1726, and the New Bayreuth Palace, located in the southeast of Germany and rebuilt in 1753. In both cases, the marquetry was cleaned, removing a considerable accumulation of protective layers and dirt interspersed with each other. The combination of softwood and hardwood allowed evaluation of the response in both hardnesses. The studies confirmed that no alterations had occurred in the microstructure of the wood after the cryogenic intervention, which completely eliminated the unwanted layering without altering the patina of the ligneous support and the modifications inherent to its historical use [40].

\section{Discussion}

Dry ice blasting is effective on weak and physical bonds such as Van der Waals forces, electrostatic or capillary forces. Thus, it cannot be applied to chemical bonds as its effectiveness will be reduced [29]. Some investigations point out that the hydrocarbon nature of the deposit increases the effectiveness of the snow blasting treatment [20,29] due to the affinity that exists between carbon dioxide and some light organic compounds such as facial grease or fingerprints [39].

A multilayered sample should respond adequately to the impact of dry ice blasting, provided that its yield point is higher than $70 \mathrm{psi}[29,32]$. In turn, it is convenient to study the glass transition temperature $(\mathrm{Tg})$ of each material, based on the surface measurement references that some authors have collected on this type of cleaning. Failing to take this consideration into account could cause severe fractures in the material to be preserved since exceeding the $\mathrm{Tg}$ of a structure causes a notable loss of flexibility, reaching a completely irreversible glassy state that will compromise its future preservation [48]. The loss of flexibility increases the risk inherent in any momentary drop of temperature, added to the lack of resistance to the vibration produced during impact. For this reason, the artwork should be anchored to a support to avoid possible displacements during projection [32].

It is advisable to measure the temperature to which the piece will be subjected in order to properly know the working values and safety ranges of the material to be preserved. However, the temperature values will be altered by several factors. The quality and storage of the projectile are variables that directly affect the measurements. Material stored in a tank that maintains stable cryogenic values $\left(-80^{\circ} \mathrm{C}\right)$ will maintain excellent quality compared to material stored in a container that is affected by air leakage and thermal variations. The climatic conditions of the room, such as temperature, humidity or airflow, as well as the reactivity of the material to be balanced with the cryogenic values and the exposure time necessary to obtain satisfactory cleaning results, will also produce variations in the thermal values. While some authors recorded minimum values of $8^{\circ} \mathrm{C}$ [39] by micro-projection of carbonic snow or intervals of $-15^{\circ} \mathrm{C}$ to $-7^{\circ} \mathrm{C}$ on cellulosic material, which reached $5{ }^{\circ} \mathrm{C}$ after $14 \mathrm{~s}$ [23], others recorded $-12{ }^{\circ} \mathrm{C}$ on ligneous supports after the application of dry ice blasting [40].

The selection of the precise method requires an in-depth compositional study of the stratified material. It is essential to know the type of bond between layers, as well as the glass transition temperature (Tg), hardness and chemical composition of each one. It is also relevant to know how the undesired deposit interacts with the underlying material. Thus, 
interlayer bonding will be a challenge that will require precision and a thorough knowledge of the technique to obtain optimal results. It should be understood that removal will only be successful in those cases where the hardness of the layer to be removed is less than the rest of the strata. In this sense, the Tg of the underlying materials must respond adequately to the thermal effect for a safe and efficient cleaning treatment. Inadequate adjustment of blasting parameters can lead to irreparable physico-mechanical alterations in the structure of the composite, resulting in shrinkage, cracking and loss of cohesion. If the safe thermal range is exceeded, further chemical degradation may occur, leading to internal instability causing loss of flexibility and embrittlement. These are severe degradative changes whose irreversibility critically limits the preservation of the material. The most susceptible material to freezing damage are plastic polymers such as pictorial layers and sculptures, as well as oily layers and some natural glues, which can be materials applied by restorers in previous treatments such as consolidation, varnishing, stuccoing or pictorial reintegration.

The working area should have low humidity levels in order to reduce the probability of condensation. Surface steam condensation is common when applying temperatures lower than those of the substrate, and this could compromise hydrophilic materials. By reducing the ambient humidity, in combination with constant airflow, this factor disappears. Other authors recommend the use of an inert gas such as nitrogen as a substitute for the airstream, with the idea of repelling moisture and reducing steam accumulation over the area. This option increases the risk involved in the intervention, and it is advisable to carry it out in hermetic chambers that allow exposure control [28].

The machine parameters and their adjustment to the surface requirements play an essential role in the assessment before the treatment. An increase in the beam pressure will allow the removal of submicron size particles [20] but be more limited in its effect on those that are between the interstices of the porous structure of the support. Attempts have been made to solve this problem by reducing the pressure and the diameter of the shot, with good results in cellulosic substrates three decades old, whose deposits were located in the fiber network of the paper, demonstrating that no damage had occurred in the material [23].

Although there is no residue generated by the cleaning method, the remnants of the removed material must be taken into account. These tend to redeposit on the surface, hindering the cleaning efficiency. Therefore, the parallel use of suction methods or slightly sticky materials to trap the dirt is recommended. Following a centrifugal cleaning pattern could solve the problem by displacing unwanted particles to the perimeter [39].

Empirical evaluation of the use of the technique is essential to know it completely. The operator's experience will be relevant to obtain good results, taking into account that the critical eye of the conservator-restorer will facilitate the precise adaptation of the method to achieve the desired results after cleaning [39].

Dry ice blasting is an eco-compatible method that requires certain safety measures for the operator. When carbon dioxide sublimation takes place, the concentration values of the ambient air increase and may exceed safe levels. It is therefore advisable to work in properly ventilated spaces or spaces with $\mathrm{CO}_{2}$ concentration measurement systems to alert the worker in the event that health and safety levels are exceeded [32]. In addition, PPE such as goggles, particle masks and hearing protection helmets should be added due to the decibels that can be reached by the equipment in operation [39].

Issues related to the sustainability of the method should be highlighted. It is important to remember that it uses micro-projections of $\mathrm{CO}_{2}$ recycled from industrial by-products, and their contribution to the release of greenhouse gases is considerably low. However, reducing this contribution further represents a new challenge in cryogenic studies, with the aim of implementing an absolutely ecological and sustainable technology without compromising the efficiency and applicability of the method. For this reason, research has been refocused on evaluating innovative solutions to solve this problem through the development of ultra freezing equipment with eco-sustainable gas projection. This line of study has generated synergies between the Department of Conservation and Restoration of Cultural Assets through the Research Microcluster Cultural and Creative Industries, 
Tourism \& Technology, the University Institute for Heritage Restoration, the University Institute CMT-Thermal Engines and the Department of Food Technologies of the Polytechnic University of Valencia; to develop a new prototype of a completely innovative, sustainable and efficient cleaning system that represents a relevant technological advance for the cultural, industrial and food sectors, offering the implementation of a green technology capable of solving problems related to the toxicity, efficiency and adaptability of other cleaning methods, while contributing to the 2030 Agenda and its commitment to environmental protection.

\section{Conclusions}

The progress towards the development of new cleaning methodologies in restoration, with the objective of environmental protection, is contributing to the opening of new lines of study that encourage the research community to incorporate these methods in their intervention proposals. That is why the inclusion of dry ice blasting in the heritage field is an alternative that supports the new goals of sustainable technological innovation, solving aspects related to both toxicity and the reduction of waste and risks arising from the retention of solvents. This leads to an improvement in the impact of our interventions in terms of personal safety, environmental impact and cultural heritage preservation. The variables in the parameters that are contemplated in most cryocleaning equipment are perfectly adaptable to the requirements for their application on cultural assets, as demonstrated in the case studies described. However, it is imperative to optimize the equipment, in addition to performing more experimental studies that support its application on different materials with different characteristics. For this purpose, increasing the knowledge on the effect of the different thermomechanical intervention agents and other aspects such as the pressure, type of nozzle or pellet size will promote the employability of the method and will provide empirical information specifically evaluated by conservation professionals, whose requirements are far from those intended for industrial use.

Author Contributions: Conceptualization, V.S.-C. and A.V.-B.; methodology, V.S.-C. and A.V.-B.; investigation, A.V.-B. and V.S.-C.; resources, V.S.-C. and A.V.-B.; writing-original draft preparation, A.V.-B.; writing-review and editing, A.V.-B., V.S.-C. and A.C.-S.; supervision, V.S.-C., A.C.-S. and M.-Á.C.-M. All authors have read and agreed to the published version of the manuscript.

Funding: This research received no external funding.

Institutional Review Board Statement: Not applicable.

Informed Consent Statement: Not applicable.

Data Availability Statement: Not applicable.

Conflicts of Interest: The authors declare no conflict of interest.

\section{References}

1. UNE-EN 17138 [Asociación Española de Normalización]. Conservación del Patrimonio Cultural, Métodos y Materiales Para la Limpieza de Materiales Inorgánicos Porosos. 2019. Available online: https:/ / portal.aenormas.aenor.com/ (accessed on 20 June 2021).

2. Vega, A. La Limpieza Criogénica en Patrimonio Cultural. Hacia Nuevos Métodos Sostenibles y Respetuosos Con el Medio Ambiente. Master's Thesis, Polytechnic University of Valencia, Valencia, Spain, 2021. Available online: https:/ /riunet.upv.es/ handle/10251/173967 (accessed on 7 October 2021).

3. Colomina, A.; Guerola, V.; Moreno, B. La Limpieza de Superficies Pictóricas. Metodología y Protocolos Técnicos; Ediciones Trea: Gijón, Spain, 2020.

4. Cremonesi, P. El Ambiente Acuoso Para el Tratamiento de Obras Polícromas; Il Prato: Villatora, Italy, 2014.

5. Barros, J.M. Re-evaluating the roles of the cleaning process in the conservation of paintings. Ge-Conserv. 2015, 7, 14-23. [CrossRef]

6. Pérez, P. Microemulsiones Soluciones Micelares y Emulsiones sin Tensoactivos en la Limpieza de Pintura Mural al Fresco. Ph.D. Thesis, Universitat Politècnica de València, Valencia, Spain, 2019. Available online: https://riunet.upv.es/handle/10251/124826\# (accessed on 22 July 2021). 
7. Laudenbacher, K. Considerations of the Cleaning of Paintings. In New Insights into the Cleaning of Paintings Proceedings from the Cleaning 2010 International Conference Universidad Politécnica de Valencia and Museum Conservation Institute; Mecklenburg, E.M.F., Charola, A.E., Koestler, R.J., Eds.; Smithsonian Institution Scholary Press: Washington, DC, USA, 2010.

8. Balliana, E.; Ricci, G.; Pesce, C.; Zendri, E. Assessing the value of green conservation for cultural heritage: Positive and critical aspects of already available methodologies. Int. J. Conserv. Sci. 2016, 7, 185-202.

9. Bosch, P.; Ranalli, G.; Joseph, E.; Ripp, S. The safety of biocleaning technologies for cultural heritage. Front. Microbiol. 2014, 5, 1-3. [CrossRef]

10. Mastrangelo, R.; Chelazzi, D.; Poggi, G.; Fratini, E.; Buemi, L.P.; Petruzzellis, M.L.; Baglioni, P. Twin-chain polymer hydrogels based on poly(vinyl alcohol) as new advanced tool for the cleaning of modern and contemporary art. Proc. Natl. Acad. Sci. USA 2020, 117, 7011-7020. [CrossRef] [PubMed]

11. Chelazzi, D.; Bordes, R.; Giorgi, R.; Holmberg, K.; Baglioni, P. The use of surfactants in the cleaning of works of art. Curr. Opin. Colloid Interface Sci. 2020, 45, 108-123. [CrossRef]

12. Aguado, E.; Bianchi, C.; García, M. La Acidez y Salinidad de Los óleos TITAN®, Su pH y Conductividad en el Contexto de la Intervención Con métodos acuosos. In Conservación de Arte Contemporáneo: $20^{a}$ Jornada; Museo Nacional Centro de Arte Reina Sofía: Madrid, Spain, 2019; pp. 79-88.

13. Pouli, P.; Oujja, M.; Castillejo, M.; Oujja, M.; Castillejo, M.; Castillejo, M. Practical issues in laser cleaning of stone and painted artefacts: Optimisation procedures and side effects. Appl. Phys. A 2012, 106, 447-464. [CrossRef]

14. Moretti, P.; Iwanicka, M.; Melessanaki, K.; Dimitroulaki, E.; Kokkinaki, O.; Daugherty, M.; Sylwestrzak, M.; Pouli, P.; Targowski, P.; Van Den Berg, K.J.; et al. Laser cleaning of paintings: In situ optimization of operative parameters through non-invasive assessment by optical coherence tomography (OCT), reflection FT-IR spectroscopy and laser induced fluorescence spectroscopy (LIF). Herit. Sci. 2019, 7, 44. [CrossRef]

15. VVAA. Proyecto COREMANS: Criterios de Intervención en Materiales Pétreos. Ministerio de Educación Cultura y Deporte. 2013. Available online: https://www.libreria.culturaydeporte.gob.es/libro/proyecto-coremans-criterios-de-intervencion-enmateriales-petreos_5336/(accessed on 15 July 2021).

16. VVAA. Proyecto COREMANS: Criterios de Intervención en Materiales Metálicos. Ministerio de Educación Cultura y Deporte. 2015. Available online: https:/ / www.libreria.culturaydeporte.gob.es/libro/proyecto-coremans-criterios-de-intervencion-enmateriales-metalicos_5335/(accessed on 15 July 2021).

17. Casoli, A.; Di Diego, Z.; Isca, C. Cleaning painted surfaces: Evaluation of leaching phenomenon induced by solvents applied for the removal of gel residues. Environ. Sci. Pollut. Res. 2014, 21, 13252-13263. [CrossRef] [PubMed]

18. Prati, S.; Volpi, F.; Fontana, R.; Galletti, P.; Giorgini, L.; Mazzeo, R.; Mazzocchetti, L.; Samorì, C.; Sciutto, G.; Tagliavini, E. Sustainability in art conservation: A novel bio-based organogel for the cleaning of water sensitive works of art. Pure Appl. Chem. 2018, 90, 239-251. [CrossRef]

19. Spur, G.; Uhlmann, E.; Elbing, F. Dry-ice blasting for cleaning: Process, optimization and application. Wear 1999, $233-235,402-411$. [CrossRef]

20. Liu, Y.-H.; Maruyama, H.; Matsusaka, S. Effect of Particle Impact on Surface Cleaning Using Dry Ice Jet. Aerosol Sci. Technol. 2011, 45, 1519-1527. [CrossRef]

21. Van der Molen, R.; Joosten, I.; Beentjes, T.; Megens, L. Dry ice blasting for the conservation cleaning of metals. In Proceedings of the Interim Meeting of the ICOM-CC Metal Working Group, Charleston, SC, USA, 11-15 October 2010; pp. $135-143$.

22. Dominguez, M.; Gauto, J.; Guerreiro, R. Limpieza Criogénica; (Proyecto final); Repositorio Institucional Abierto-Universidad Tecnológica Nacional: Buenos Aires, Argentina, 2011.

23. Ludmila, S.J.; Vávrová, P.; Neoralová, J.; Součková, M.; Novotná, D.; Jandová1, V.; Ondráček, J.; Ondráčková, L.; Kř́ižová, T.; Kocová, K.; et al. Carbon Dioxide Snow Cleaning of Paper. Research Square. 2021. Available online: https://europepmc.org/ article/ppr/ppr358786 (accessed on 19 July 2021).

24. Kohli, R.; Mittal, K.L. Developments in Surface Contamination and Cleaning. In Developments in Surface Contamination and Cleaning; Elsevier Inc.: Amsterdam, The Netherlands, 2016; Volume 10. [CrossRef]

25. Asamblea General de las Naciones Unidas. Transformar nuestro mundo: La Agenda 2030 para el Desarrollo Sostenible. Seguim. de Los Result. De la Cumbre Del Milen. 2015. [CrossRef]

26. Liu, Y.-H.; Matsusaka, S. Formation of Dry Ice Particles and Their Application to Surface Cleaning. Earozoru Kenkyu 2013, 28, 155-162. [CrossRef]

27. Kohli, R. Applications of Solid Carbon Dioxide (Dry Ice) Pellet Blasting for Removal of Surface Contaminants. In Developments in Surface Contamination and Cleaning: Applications of Cleaning Techniques; Kohli, R., Mittal, K.L., Eds.; Elsevier: Amsterdam, The Netherlands, 2019; Volume 11, pp. 117-169. Available online: https:/ /www.elsevier.com/books/developments-in-surfacecontamination-and-cleaning-volume-12/kohli/978-0-12-816081-7 (accessed on 15 June 2021).

28. Cano, F. Carbon dioxide dry ice snow cleaning. In Handbook for Critical Cleaning; Kanegsberg, B., Ed.; CRC Press: Boca Raton, FL, USA, 2001; pp. 329-336.

29. Sherman, R. Carbon Dioxide Snow Cleaning. Part. Sci. Technol. 2007, 25, 37-57. [CrossRef]

30. Cold Jet. La Limpieza Criogénica. 2021. Available online: https://www.coldjet.com/es/la-limpieza-criogenica/ (accessed on 22 July 2021). 
31. Cotec, F. Innovación en el sector del Patrimonio histórico. In Informes Sobre el Sistema de Innovación Español; Fundación Cotec para la Innovación Tecnológica: Madrid, Spain, 2010.

32. Sherman, R.; Shockey, L.H. Ice Cold: Solid Carbon Dioxide Cleaning Symposium; (Sesión 1); Smithsonian American Art Museum: Washington, DC, USA, 2015; Available online: https://americanart.si.edu/videos/conservation-symposium-ice-cold-solidcarbon-dioxide-cleaning-154409 (accessed on 19 July 2021).

33. Barros, J.M. Imágenes y Sedimentos: La Limpieza en la Conservación Del Patrimonio Pictórico; Institució Alfons el Magnànim-Diputació de València: Valencia, Spain, 2005.

34. Pérez, P.; Regidor, J.L.; Roig, P. Sistema emulsionado sin tensoactivos como alternativa al uso de un Solvent Gel. Conserv. Patrim. 2020, 34, 101-108. [CrossRef]

35. Pérez, P.; Regidor, J.L.; Roig, M.P. Microemulsiones vs. Emulsiones sin tensoactivos. In Emerge 2018. Jornadas de Investigación Emergente en Conservación y Restauración de Patrimonio; Llamas, R., Alapont, J.L., Eds.; Universitat Politècnica de València: Valencia, Spain, 2018; pp. 146-152.

36. Kremer. Material Safety Data SheetI; Grupo Español IIC: Madrid, Spain, 2003; Available online: https://www.ge-iic.com/files / fichas\%20productos/cyclododecane.pdf (accessed on 10 November 2021).

37. Ormsby, B.; Kampasakali, E.; Learner, T. Surfactants and Acrylic Dispersion Paints: Evaluating Changes Induced by Wet Surface Cleaning Treatments. Smithsonian Contributions to Museum Conservation. 2013. Available online: http://hdl.handle.net/1008 8/20503 (accessed on 7 January 2019).

38. Jassim, A.; Khalaf, H. Dry Ice Cleaning Based Sustainable Cleaning Technology for Oil and Gas Storage Tanks. In Proceedings of the 1st International Multi-Disciplinary Conference Theme: Sustainable Development and Smart Planning, IMDC-SDSP 2020, Online, 28-30 June 2020. [CrossRef]

39. Shockey, L.H. Blow it off: Moving beyond compressed air with carbon dioxide snow. Objects Spec. Group Postprints 2009, 16, 13-24.

40. Piening, H.; Schwarz, R. Using low temperatures for cleaning surfaces. Three modes of application. Restauro Forum Restaur. Konserv. Denkmalpfl. 1998, 104, 248-252.

41. Sanmartín, P.; Cappitelli, F.; Mitchell, R. Current methods of graffiti removal: A review. In Construction and Building Materials; Elsevier: Amsterdam, The Netherlands, 2014; Volume 71, pp. 363-374. [CrossRef]

42. Cold Jet. AERO2-PCS 60. Operator \& Maintenance Manual; Cold Jet: Loveland, OH, USA, 2019; Available online: https: //www.coldjet.com/wp-content/uploads/0471_SPEC-SHEET_AERO2_PCS60_2020_A4_SP_sv.pdf (accessed on 22 July 2021).

43. Gases, N. Aplicaciones. 2019. Available online: https:/ / hieloseco.es/applications (accessed on 3 December 2019).

44. Cold Jet. Dry Ice Cleaning Is Used to Clean Metal and Ceramic Artifacts before They Are Displayed at Auschwitz-Birkenau Memorial. 2011. Available online: https://www.coldjet.com/es/resources/auschwitz-memorial-historical-restoration/ (accessed on 19 July 2019).

45. Cutulle, C.; Kim, S. Dry ice blasting in the conservation of metals: A technical assessment as a conservation technique and practical application in the removal of surface coatings. In Proceedings of the American Institute for Conservation of Historic and Artistic Works. Objects Specialty Group, Miami, FL, USA, 13-16 May 2015; Volume 22, pp. 77-100.

46. Posner, K. Conservation Comes Outdoors for Henry Moore's “Bronze Form”. Getty Iris Blog. 2012. Available online: http: / / blogs.getty.edu/iris/conservation-comes-outdoors-for-henry-moores-bronze-form/ (accessed on 19 July 2021).

47. Hoshaw, L. Soy and Dry Ice Among San Francisco's New Tricks to Banish City Graffiti; KQED: San Jose, CA, USA, 2013; Available online: https:/ / www.kqed.org/science/10953/soy-and-dry-ice-among-san-franciscos-new-tricks-to-banish-city-graffiti (accessed on 19 July 2021).

48. Mecklenburg, M.F.; Tumosa, C.S.; Erhardt, D. The Changing Mechanical Properties of Aging Oil Paints. MRS Online Proc. Libr. 2005, 852, 13-24. [CrossRef] 